\title{
Correction: Outcomes in first relapsed-refractory younger patients with mantle cell lymphoma: results from the MANTLE-FIRST study
}

Carlo Visco (1) Alice Di Rocco - Andrea Evangelista - Francesca Maria Quaglia - Maria Chiara Tisi - Lucia Morello • Vittorio Ruggero Zilioli - Chiara Rusconi - Stefan Hohaus $(\mathbb{D} \cdot$ Roberta Sciarra - Alessandro Re - Cristina Tecchio • Annalisa Chiappella $\cdot$ Ana Marin-Niebla (1) - Rory McCulloch · Guido Gini $\cdot$ Tommasina Perrone $\cdot$ Luca Nassi $\cdot$ Elsa Pennese - Piero Maria Stefani - Maria Christina Cox • Valentina Bozzoli - Alberto Fabbri • Valentina Polli • Simone Ferrero - Maria Isabel Alvarez De Celis - Antonello Sica • Luca Petrucci - Luca Arcaini (i) - Simon Rule (iD) Mauro Krampera $($ ID $\cdot$ Umberto Vitolo • Monica Balzarotti

Published online: 22 January 2021

(c) The Author(s), under exclusive licence to Springer Nature Limited 2021

Correction to: Leukemia

$$
\text { https://doi.org/10.1038/s41375-020-01013-3 }
$$

In the article entitled "Outcomes in first relapsedrefractory younger patients with mantle cell lymphoma: results from the MANTLE-FIRST study", the affiliation of
Lucia Morello and Monica Balzarotti should be corrected as follows:

${ }^{6}$ Humanitas Clinical and Research Center-IRCCS, Humanitas Cancer Center, via Manzoni 56, 20089 Rozzano, Milan, Italy

We regret the error. 